\title{
Análise comparativa da formação do "zip" apical em canais curvos e atresiados produzido "in vitro" por duas técnicas de instrumentação
}

\author{
José Antonio Poli de Figueiredo* \\ Nicolau Fonseca Milano** \\ Paulo M. H. Dummer***
}

RESUMO

O objetivo do presente estudo foi avaliar a formação do "zip" apical em canais curvos e atresiados produzido por duas técnicas de instrumentação. Para tanto, 50 canais simulados em resina "epoxi" foram confeccionados a uma curvatura de $40^{\circ}$ e divididos em dois grupos de 25 canais cada um. O primeiro grupo foi preparado pela Técnica Convencional e

o segundo pela Técnica Escalonada. Depois de feitos os reparos, os canais foram avaliados por dois observadores. Diante dos resultados obtidos, chegou-se às seguintes conclusōes: a) a Técnica Convencional produziu zip apical em maior número do que a Técnica Escalonada; b) a Técnica Escalonada proporcionou maior segurança no preparo, tendo obtido, na maioria dos casos, uma forma cônica afunilada contínua, com o desgaste sendo menor no ápice e maior no orifício de entrada do canal.

\section{SUMMARY}

The aim of this study was to evaluate the formation of the apical zip in thin and curved canals. For that purpose, 50 simulated canals were built in epoxi resin in a curvature of $40^{\circ}$ and divided into two groups of 25 each. The first group

was prepared by the Standardized Preparation Technique and the second group was prepared by the Step-back Technique. After the preparation, the canals were evaluated by two observers. From the results obtained, the conclusions are as follows: a) The Standardized Preparation Techinique produced more apical zips than the Step-back Techinique;

b) The Step-back Tchnique provided more reliability, for it obtained in most cases a continuously shaped conical form from apical to coronal.

\section{INTRODUÇÃO}

A necessidade do preparo do canal antes da obturação do mesmo é reconhecida há muito tempo como passo importante na terapia endodôntica (INGLE, 1961). Esse preparo 6 realizado com a utilizaçăo de dois procedimentos concomitantes: preparo biomecânico $\theta$ irrigaçāo-aspiraçăo. SCHILDER (1974) descreve-os como limpeza e preparo da forma do canal radicular.

Atualmente, a forma do canal que se aceita como apropriada para receber uma obturaçāo pela técnica da condensaçāo lateral e/ou vertical é cônica afunilada contínua, com o diâmetro transverso menor à medida que se aproxima do ápice (SCHILDER, 1974; SCHILDER \& YEE, 1984).

Infelizmente, lograr êxito no preparo da forma do canal năo é um objetivo fácil, principalmente em canais curvos, e muitos relatos descrevem o desenvolvimento de degraus, perfuraçōes e outras aber- raçōes, como o "cotovelo" e o "zip" apical (WEINE et alii, 1975; WALTON \& TORABINEJAD, 1989; BARRIENTOS et alii, 1985; LIM \& WEBBER, 1985; GUTMANN et alii, 1988; WILDEY \& SENIA, 1989; ALODEH et alii, 1989; DUMMER et alii, 1989; ALODEH \& DUMMER, 1989).

Frequentemente o menor diâmetro do canal preparado nāo é no ápice, mas próximo à porçảo média da cunatura, local este denominado de "cotovelo" (WEINE, 1975). Isso deixa a terminaçāo apical com uma forma de gota de lágrima, que WEINE et alii (1975) denominaram de "zip" apical. Comparado com a perfuraçāo, onde há duas saídas do canal separadas (a saída anatómica verdadeira e a saída falsa perfurada), esse tipo de aberraçāo tem uma única saída, representando uma área de alargamento contínuo, dando a impressảo em dentes extraídos de que houve um transporte da posiçāo do forame com um aspecto de gota de lágrima (WEINE, 1976).
Esse "zip" apical provoca dificuldades para o selamento hermético do canal radicular. O cone nāo consegue moldar-se à forma do canal preparado na porçāo apical, onde pela técnica da condensaçăo lateral e/ou vertical da gutapercha, poderemos ter um espaço vazio ou preenchido somente por cimento, mas sem gutapercha. Além disso, temos o risco de perfurar a raiz no terço apical, se instrumentos muito calibrosos forem utilizados para alargar o canal, ou se a raiz tiver paredes muito finas.

Embora seja grande o número de técnicas de preparo da forma existentes, bem como as diversas variantes sugeridas, a realidade da endodontia brasileira nos le-

\footnotetext{
* Mestre em Endodontia - UFPel

** Prof. Titular da Disciplina de Endodontia UFRGS

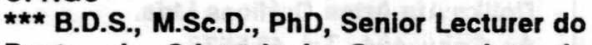
Depto. de Odontologia Conservadora da University of Wales College of Medicine
} 
va a duas técnicas de uso consagrado: a Técnica Convencional e a Técnica Escalonada.

Propomo-nos neste trabalho analisar "in vitro" a formaçăo do "zip" apical em canais curvos e atresiados frente às técnicas de instrumentaçăo Convencional e Escalonada, fazendo uso de canais simulados em corpos de prova de resina "epoxi".

\section{MATERIAL E MÉTODO}

\section{Confecçăo dos corpos de prova}

Cinqüenta canais simulados em blocos de resina "epoxi" foram confeccionados do seguinte modo:

a) cones de prata de número 20 foram temperados em estufa a $700^{\circ} \mathrm{C}$ durante 3 minutos. Logo após, os cones foram removidos da estufa e colocados em água fria. Esse procedimento permitia que os cones fossem curvados com maior facilidade e não retornassem a sua posiçāo original;

b) usando um conformador de canal, os cones foram pré-curvados antes do uso;

c) o cone era entăo removido do conformador. Na ponta do cone era colocada uma bolinha de cera construída com um mesmo porta-amálgama, para garantir a padronizaçāo do tamanho. A bolinha de cera era perfurada previamente com uma agulha, para evitar que, ao colocar-se a mesma na ponta do cone, se forçasse o mesmo e alterasse a curvatura pré-determinada de $40^{\circ}$;

d) sobre uma bandeja de alumínio foi despejado ágar-ágar aquecido até a metade da sua profundidade; depois de esfriado e endurecido, procedia-se a colocação dos cones para dentro da superfície de ágar-ágar até chegar à marca pré-determinada pela caneta, de forma que os $16 \mathrm{~mm}$ restantes de cone com a cera ficassem para fora, perpendiculares à superfície;

e) cubetas d acrílico transparente de espectrofotômetro foram cortadas em $28 \mathrm{~mm}$ e usadas para reter a resina;

f) a resina 1 foi entāo preparada, em uma proporçăo de $\mathbf{2 0 0}$ gramas de base para 56 gramas de catalisador. A mistura foi levada a um vibrador ultrassónico e deixada sob intensa vibraçāo durante dois minutos, para remover o maior número de bolhas possível. Logo após, a mistura foi despejada por intermédio de um funil em todas as cubetas, preenchendo-as totalmente uma por uma;

g) deixou-se a resina polimerizar por um período de 24 horas em temperatura ambiente. Os blocos foram removidos da superfície de ágar-ágar e colocados em uma bandeja de água morna com detergente, para remover qualquer impureza que se houvesse depositado na superfície dos blocos. Depois de 30 minutos, os blocos eram secos e, com um alicate, removia-se o cone de prata que, ao sair de sua posiçāo original, deixava um espaço vazio que simulava um canal radicular.

Todos os canais ficaram com a mesma curvatura $\left(40^{\circ}\right)$, com a mesma posição de início de curvatura (a $12 \mathrm{~mm}$ da abertura do canal) e com o mesmo raio de arco do canal (16mm). Ver Fig. 1.

\section{Preparo dos Canais}

Todos os canais foram preparados manualmente, fazendo-se uso das limas $\mathrm{K}$ Flex 2. Foram preparados ao todo $50 \mathrm{ca}$ nais, divididos em dois grupos, como segue:

\section{GRUPO I - Técnica Convencional}

O objetivo do preparo com a Técnica Convencional foi 0 de alargar todo 0 comprimento de trabalho até a lima de número 35 . Primeiramente uma lima de número 10 foi introduzida até menos $1 \mathrm{~mm}$ do comprimento total do canal e entāo foi manipulada com movimentos de vaivém, sendo que 0 instrumento entrava livremente no canal e efetuava sua açāo de limagem por traçăo contra uma das paredes, progredindo o preparo de forma circunferencial ao redor das paredes do canal. O uso da lima de número 10 seguiu dessa forma até que uma lima de número 15 penetrasse em todo comprimento de trabalho sem força. O preparo continuou dessa maneira com as limas de números $15,20,25,30$ e 35 , até que o número 35 fosse capaz de penetrar em todo comprimento de trabalho sem força. Irrigaçāo copiosa com Dehyquart - A 2/1000 3 foi utilizada pelo menos duas vezes para cada número de lima. A recapitulaçāo, com a lima anterior apos o prparo com cada lima, foi executada regularmente. Todas as limas foram pré-curvadas em $40^{\circ}$ antes do uso. Ao todo, 25 canais foram prepa- rados por essa técnica.

\section{GRUPO II - Técnica Escalonada}

O objetivo do preparo com a Técnica Escalonada foi o de alargar a extremidade final do preparo até a lima de número 25 e escalonar o remanescente do canal até o número 35 . O preparo começou com a lima de número 10 e progrediu de maneira seriada até que o número 25 fosse capaz de passar em todo o comprimento de trabalho sem força. O preparo do canal remanescente foi levado com a Técnica Escalonada usando limas de números 30 e 35 até menos 1 e $2 \mathrm{~mm}$ do comprimento inicial de trabalho, respectivamente. Irrigaçāo copiosa e recapitulaçăo foram feitas como descrito na Técnica Convencional. Os movimentos de limagem seguiram a mesma dinâmica da técnica anterior. Ao todo, 25 canais foram preparados pela Técnica Escalonada.

Todos os canais foram preparados por um único operador. Durante o procedimento de preparo, cada bloco de resina foi coberto por fita isolante, para garantir que o processo fosse realizado "às cegas". No entanto, o comprimento de trabalho, a direçāo da cunva e a forma de cada canal já eram conhecidos.

As limas foram utilizadas para preparar no máximo três canais, sendo depois descartadas. As limas que se distorceram ou fraturaram antes do tempo de uso determinados foram substituídas imediatamente.

\section{Avaliaçáo dos Preparos}

Dois observadores avaliaram as imagens dos blocos, quanto à presença ou ausência do "zip" apical e registraram, separadamente, em termos numéricos, a presença de tal aberraçāo em cada técnica estudada. A utilizaçẩo do segundo observador garantiu não haver qualquer interferência pessoal na avaliação dos canais preparados.

\section{RESULTADOS}

Os dados levantados pelos dois observadores foram registrados e estāo expressos nas Tabelas I e II. Ver Figs. 2 e 3.

\section{TABELA I}

Quantidade numérica e percentual de canais simulados que apresentaram "zip" apical pela Técnica Convencional.

\begin{tabular}{cccc}
\hline Observadores & "Zip" Presente & “Zip” Ausente & Total \\
\hline A & $19(76 \%)$ & $06(24 \%)$ & $25(100 \%)$ \\
B & $18(72 \%)$ & $07(28 \%)$ & $25(100 \%)$ \\
\hline
\end{tabular}

(1) Stycast Resin - 1266, Emerson and Cumming. Westerlo - Belgium

(2) Sybron Keerr. Ind. Com. Ltda.

(3) Feito por Química Delaware, Porto Alegre

R. Fac. Odontol.

Porto Alegre
V. 32

1

p.2-5

N. 2

\begin{tabular}{l|l} 
N.2 & p.2-5
\end{tabular}


TABELA II

Quantidade numérica e percentual de canais simulados que apresentaram "zip" apical pela Técnica Escalonada.

\begin{tabular}{cccc}
\hline Observadores & “Zip" Presente & “Zip” Ausente & Total \\
\hline A & $08(32 \%)$ & $17(68 \%)$ & $25(100 \%)$ \\
B & $08(32 \%)$ & $17(68 \%)$ & $25(100 \%)$ \\
\hline
\end{tabular}

\section{DISCUSSÃO}

Os canais simulados foram utilizados nesses estudo por uma série de razōes, muitas das quais já foram colocadas por outros pesquisadores (WEINE et alii, 1975; LIM \& WEBBER, 1985; YAMAGUCHI et alii, 1988; DUMMER et alii, 1989; ALODEH et alii, 1989). Esses canais podem ser manufaturados em distintos comprimentos, posiçōes e graus de curvatura, parâmetros que podem ter efeito no resultado final do preparo que, dificilmente, seriam determinados e controlados em dentes humanos extraídos. A forma original do canal simulado é padronizada, o que nos permite compará-la com o preparo final após a instrumentaçāo. Além disso, o trabalho de LIM \& WEBBER (1985) nos sugere que canais simulados em resina sāo um substituto válido dos dentes naturais para avaliaçāo de técnicas de preparo.

Padronizamos os canais com a mesma curvatura $\left(40^{\circ}\right)$, com a mesma posiçāo de início da curvatura (a $12 \mathrm{~mm}$ do orifício de entrada) e com o mesmo raio do arco do canal $(16 \mathrm{~mm})$. Nossa intençăo de utilizar o mesmo tipo de canal simulado foi de eliminar o máximo de variáveis existentes no experimento, para que as técnicas de instrumentaçảo fossem avaliadas e nảo os diferentes graus de curvatura. EscoIhemos esse tipo de canal, pois correspondia aos padrōes de um canal com curvatura acentuada.

Os resultados obtidos pelos dois observadores não deixam dúvida de que a Técnica Escalonada foi muito mais eficiente do que a Técnica Convencional para evitar a formaçăo do "zip" apical.

A Técnica Escalonada, segundo WALTON \& TORABINEJAD (1989), tem os seguintes objetivos mecânicos: buscar uma conicidade contínua ápico-oclusal, permitir uma matriz dentinária apical, manter a forma original do canal radicular e manter a forma e posiçảo espacial do forame apical. Além disso, tem as seguintes vantagens: permitir maior capacidade de limpeza, maior penetraçāo da soluçāo irrigadora e uma obturaçăo mais hermética do canal. Nesse estudo, os objetivos mecå- nicos da Técnica Escalonada foram atingidos em $69 \%$ dos casos, o que a destaca em relaçāo à Técnica Convencional, que so obteve sucesso em 24 a $28 \%$ dos casos, no que tange à forma e posiçāo de forame apical.

A quantidade do desgate apical em cada técnica deve ter sido fator preponderante na diferença de resultados entre as técnicas, pois segundo vários autores (BARRIENTOS et alii, 1985; ELDEEB e BORAAS, 1985; WEINE, 1989; GUTMANN et alii, 1988), o preparo apical até a lima de número 25 permite maior segurança para se evitar o "zip" apical. A partir desse número, a incidência do "zip" apical aumenta consideravelmente em canais

Acreditamos que as diversas técnicas e manobras alternativas propostas por diversos pesquisadores podem interferir no resultado da forma final do preparo, constituindo-se em um vasto campo de investigaçāo científica para novos trabalhos.

\section{REFERÊNCIAS BIBLIOGRÁFICAS}

01. ALODEH, M.H.A. et alii. Shaping of simulated root canals in resin blocks using the step-back technique with K-files manipulated in a simple in/out filing motion. Int. Endod. J., 22:107-17, 1989.

02. ALODEH \& DUMMER, P.M.H. A comparison of the ability of K-files and Hedstrom files to shape simulated canals in resin block. Int. Endod. J., 22:226-35, 1989.

03. BARRIENTOS, P. \& ARCE, M. Trad. PESCE, H.F. Efeito de quatro tipos de instrumentos no preparo de canais atresiados e curvos. Rev. Paul. Odont., 7(1):9-13, jan/fev, 1985.

04. CLEM, W.H. Endodontics: the adolescent patient. Dent. Clin. N. Amer., 13(2): 483-93, Apr., 1969.

05. DUMMER, P.M.H. et alii. Shaping of simulated root canals in resin blocks using files activated by a sonic handpiece. Int. Endod. J., 22:211-25, 1989.

06. ELDEEB, M.E.; BORAAS, J.C. The effect of different files on the preparation shape curvos. of severily curved canals. Int. Endod. J., 18(1):1-7, Jan., 1985.

07. ESTRELA, C.; FIGUEIREDO, J.A.P.; DORNELLES, J.M. Aspectos preventivos e terapêuticos das perfuraçōes iatrogênicas em Endodontia. Rev. Odonto Ciência, 9(1):53-9, 1900.

08. GUTMANN, J.L. et alii. Problem solving in Endodontics. $1^{2}$ ed., Chicago, Year Book Medical Publishers, 1988. p. 32-51.

09. INGLE, J.I. A standardized endodontic technique using newly designed instruments and filling materials. Oral Surg. Oral Med. Pathol., 14:83-91, 1961.

10. LIM, K.C. \& WEBBER, R. The validity of simulated root canals for the investigation of the prepared root canal shape. Int. Endod. J., 18(4) :240-6, Oct., 1985.

11. MARTIN, H.A. Telescope technique for Endodontics. J. Dist. Columbia Dent. Soc., 49(2):12-9, 1974.

12. MULLANEY, T.P. Instrumentation of finely curved canals. Dent. Clin. N. Amer. 23(4):575-92, Oct., 1979.

13. SCHILDER, H. Cleaning and shaping the root canal. Dental Clinics of North America, 18(2):269-96, Apr., 1974.

14. SCHILDER \& YEE, F.S. Canal debridement and disinfection. In: Pathways of the pulp (eds. COHEN, S. \& BURNS, R.C.) 3rd. edn. p. 175-204. C.V. Mosby Co., Saint Louis, 1984.

15. SCHNEIDER, S.W. A comparison of canal preparations in straight and curved root canals. Oral Surg., 32(2):271-5, Aug., 1971.

16. WALTON, R. Histologic evaluation of different methods of enlarging the pulp canal space. J. Endod., 2(10):304-11, Oct., 1976.

17. WALTON \& TORABINEJAD, M. Cleaning and shaping. In: Principles and practice of Endodontics. Philadelphia, Saunders, 1989. p. 195-222.

18. WEINE, F.S.; KELLY, R.F. \& LIO, P.J. The effect of preparation procedures on original canal shape and on apical foramen shape. J. Endod., 1(8):255-62, Aug., 1975.

19. WEINE, F.S. Intracanal treatment procedures, basic and advanced topics. In: Endodontic Therapy. 4. ed., Saint Louis, Mosby, 1989. p. 277-369.

20. WILDEY, W.L. \& SENIA, S. A new root canal instrument and instrumentation technique: a preliminary report. Oral Surg., 67(2):198-207, Feb., 1989.

21. YAMAGUCHI, M. et alii. The use of ultrasonic instrumentation in the cleansing and enlargement of the root canal. Oral Surg., Oral Med., Oral Pathol., 65:249-53, 1988. 



FIG. 3: Aspecto da forma final do canal preparado, onde năo houve a formaçăo do "zip" apica

FIG. 2: Aspecto da forma final do canal preparado, onde houve a formação do "zip" apical

R. Fac. Odontol. 